\section{TYPICAL AND SEVERE CASE OF SPORADIC CRETINISM IN WHICH THE PATIENT MENSTRUATED REGULARLY.}

BY BYROM BRAMWELL, M.D., F.R.C.P., F R.S. EDIN., PHYSICIAN TO THE ROYAL INFIRMARY, EDINBURGH; LECTURER ON THE PRINCIPLES AYD PRACTICI OF MEDICTNE AND ON CLINICAL MEDICINE IN THE SCIOOL OF MEDICINE, EDINBURGH, EIC.

THE chief point of interest in this extremely well-marked case of sporadic cretinism is that the patient who was thirty-six years of age and measured exactly $36 \mathrm{in}$. in height had since the age of twenty-five years menstruated regularly every month. This is quite peculiar. I am not acquainted with any other case of typical and severe sporadic cretinism in which menstruation has occurred. The notes of the case are as follows.

The patient, aged thirty-six years, was first seen on Jan. 26th, 1895, and was again seen on Nov. 15th in the same year. Her stepmother stated that she had known the patient from the age of three years. She then had a somewhat peculiar look and vacant expression of countenance. Her birth had been unattended with difficulty. During infancy she had several attacks of bronchitis which were supposed to have retarded her development. She did not begin to walk until she was three years old and she had hardly grown in height since that time but had become very much broader. When she was seven years old the patient had an abscess on the outer part of the left leg. She had also twice had a glandular abscess of the neck; the last abscess occurred when she was sixteen years of age. She had never had any of the diseases peculiar to childhood, though she had been exposed to some of them. She had slept, for example, in a room with one of her sisters who was suffering from scarlet fever during the whole course of the disease but did not take it.

The family history of the patient showed that her mother had died at the age of thirty-one years from consumption and that her father had died at the age of fifty-four years from gangrene of the foot following rheumatism. There were six children in the family: (1) a female, now aged forty years, unmarried, and quite well and normal in every respect; (2) a male who died from phthisis at the age of twenty-eight years, a fine, tall man, $6 \mathrm{ft}$. in height, who had been in the Cameron Highlanders ; (3) a female, aged thirty-eight years, married, well formed and of average height but not very strong: (4) a female who died a few months after birth; (5) the patient; and (6) a male who died a few months after birth while teething. There were also six stepbrothers and sisters ; all were well developed and strong. No other case of sporadic cretinism or myxcedema had, so far as was known, occurred in the families of either the father or the mother.

The patient's present condition is typical of a marked degree of sporadic cretinism. Her height is exactly 36 in. and her body is very broad; the back is markedly curved in the lumbar region and the abdomen is very large and prominent. There is no umbilical hernia. The facial expression is highly characteristic. The fase is swollen and full ; the skin of the eyelids is translucent; the nose is squat and broad, pug-shaped; the ears are rather large; the mouth is large; the lower lip is pouting but the lips are not much swollen; the tongue is not protruded between the teeth and, though large, is not proportionately so large as one might expect; the teeth in the upper jaw are all wanting; and the palate is very broad and flat. The head is covered with a profusion of dark-brown hair which is very coarse. Up to the age of twenty-five years it was kept short as her head was scurfy and scaly. Since the patient began to menstruate the scalp had become much cleaner and the hair has been allowed to grow long. The anterior fontanelle is closed; the patient's stepmother says it was very late in closing but she does not remember the exact date at which it closed. The neck is very broad. Enormous fatty swellings are present above the clavicles. I have never seen these supra-clavicular swellings proportionately so large in any other case. There is also some fatty swelling in the anterior fold of the left axilla. The forearms are colossal and the tibiæ are somewhat bent $\mathbf{n}$ vards. The hands are enormously broad and large. I have not seen the hands proportionately so large in any other case. The fingers are very broad and flat and the feet are very broad and short. The hands and the feet easily become blue and cold. In complexion the patient is somewhat earthy-coloured. The skin generally is dark, dingy, brownish-yellow in colour, very dry, coarse, and harsh. She never perspires. She is worse in cold weather and her stepmother states that no matter how near the fire the patient gets she is always cold. Her appetite is small and she does not like sweets. The bowels act regularly and medicine is never required. Urination is natural. The nipples and areolæ are somewhat developed and there is a fulness in the position of the breasts. Since the age of twenty-five years the patient has menstruated every month; on one occasion (a year and a half ago) the discharge stopped for three months. There are no pubic hairs. She is naturally of a very cheerful disposition, fond of fun and company, but her intellectual development is that of a child of five or six years. She understands a great deal that is said to her, but her vocabulary is limited and she does not speak much. Before I knew that she was able to understand what was said to her I remarked that she was a comical little person, whereupon she immediately began to laugh. She told me that she was going to a wedding and that she was going to wear a blue dress. She is, it seems, very vain and fond of dress. She sleeps well-in fact, too well.

The following are the exact measurements: height, 36 in.; circumference of the abdomen at the level of the umbilicus, $24 \mathrm{in}$.; of the chest at the level of the nipples, $22 \mathrm{in.}$; of the neck over the thickest part of the glandular swellings, 19 in. ; of the neck higher up, $14 \mathrm{in}$; of the upper arm at the middle, $6 \frac{3}{4}$ in.; of the forearm at the thickest part, $7 \frac{3}{4}$ in. ; of the hand, $9 \frac{1}{8}$ in. ; length of the hand from the wrist to the tip of the middle finger, 4 in. ; circumference of foot at the thickest part, $8 \mathrm{in}$.; and length of foot, 6 in.

I did my best to persuade the stepmother to allow the patient to come into the infirmary but she would not consent to this. I then tried to induce her to have the thyroid treatment carried out at home. She consulted with the patient's sister on this point but they both refused to have the treatment carried out. They said that they had known the patient so long in her present condition and were so much attached to her that they would not like to have her changed even for the better.

Edinburgh.

\section{Clinital âtotes:}

\section{MEDICAL, SURGICAL, OBSTETRICAL, AND THERAPEUTICAL.}

\section{A CASE OF DOUBLE EMPYEMA OF THE FRONTAL} SINUS WITH ONE INFUNDIBULUM.

BY W. R. H. SteWART, F.R.C.S. EdiN.,

SURGEON TO THE EAR, THROAT, AND NOSE DEPARTMENT OF THE GREAT NORTHERN CENTRAI, HOSPITAL; CONSULTING SURGEON TO THE LONDOX TEROAT HOSPITAL.

A PATIENT, twenty-nine years of age, consulted me about two years ago for stuffiness of the left side of the nose, with a discharge of some duration, and occasional severe frontal headache. Examination showed polypi with an abundant milky-white discharge on the left side. The right side was apparently normal. There was no bulging or disfigurement of the face. The radical operation was explained to the patient, who, however, would not have it done, preferring the milder mode of treatment. The polypi were therefore removed together with the anterior ends of the middle turbinates. A free discharge remained but all sense of stuffiness and headache disappeared. About eight months ago, however, she wished for the major operation as the discharge continued so profuse. All the symptoms pointing to unilateral disease, I operated through the brow incision with a small trephine. The bony septum between the sinuses was found to be situated well over to the left side and was complete with the exception of a small hole posteriorly through which pus was oozing. The septum was removed, but there was so much granulation tissue in the right sinus that I continued my incision down the ridge, across the top of 
the nasal bones (taking care to avoid the spot where the spectacle frame might rest), and up the other ridge, and the flap was turned up. The bone was then chipped away with forceps until there was space enough to thoroughly clear out the right sinus. The reason why there was no discharge into the right side of the nose was then explained, for with the finest probe I could find no sign of an infundibulum on that side. The sinus discharged through the opening at the back of the septum into the left infundibulum. The usual funnel-shaped indiarubber tube was passed through this into the nose and the wound was closed. The patient did very well.

The points to be noticed in this case are-(1) the absence of the infundibulum on the right side which led me to believe that the right sinus was healthy and did not need interference, there being sufficient disease on the left side to oause all symptoms; and (2) the amount of room gained and the very small apparent scar left by the incision, which I have since employed with success in more than one case of auble empyema.

Devonshire-street, $\mathrm{W}$.

\section{PHTHISIS WITH PECULIAR CARDIAC PHYSICAL SIGNS. \\ BY W. SouThWICK WILLMORE, M.R.C.S. ENG.,} L.R.C.P. LOND.

THE case of phthisis with peculiar cardiac physical signs zeported by Dr. Hale White in THE LANCET of Nov. 19th, is of such interest that no apology is needed for recording an exactly similar case which came under my notice a few days ago.

The patient was a soldier and was under treatment in the Royal Victoria Hospital at Netley. He was twenty-seven years of age.. When I first saw him a week before his death he was evidently in the last stage of phthisis, with extreme debility, emaciation, cough, and abundant expectoration. Examination showed that the right lung was extensively diseased from apex to base. There were evidences of considerable cavitation at the apex and of a moderate amount of fluid at the base. The left lung was also diseased but in much Fess degree, the apices only of both lobes giving morbid physical signs. On examination of the heart at first I could make out no impulse and, moreover, there was no cardiac dulness to the left of the sternum. In the usual situation of the apex the heart sounds were very faint, almost inaudible, but on tracino them to the right they became more audible and were of almost normal intensity in the fifth right intercostal space, $2 \frac{3}{4}$ in. from the mid-sternal line; here also a feeble but perfectly distinct impulse could be felt. There was no visible pulsation in any part of the pericardium. The man's condition with distressing orthopncea did not permit of a prolonged examination, but there was apparently an area of absolute cardiac dulness commencing above at the fourth intercostal space and extending to the right to within one inch of the vertical nipple line, although the pleural effusion and the consolidation of the lung made it very difficult to be sure of this.

My first impression was that the heart had been dragged Bver by fibrosis of the right lung and pleural adhesions but, considering that the duration of the disease had been only nine months, that there was no retraction of the chest-wall, and that the physical signs were in no way suggestive of pulmonary fibrosis, the case seemed impossible of explanation in this way, and my opinion was that it was a case of dextrocardia. I examined the patient's chest once again before wis death and then noted no change in the physical signs. He died on Nov. 15th.

At the post-mortem examination it was found that the hieart was of natural size and that it was in no way displaced from its normal position. The condition of the lungs was consistent with the physical signs elicited during life. There were several large cavities in the upper part of the right lung and the whole lung was diseased and partly consolidated, although not completely airless. There were about $15 \mathrm{oz}$. of fluid in the right chest. The anterior border of the left lung covered completely the anterior surface of the heart nearly to the mid-sternal line.

The intensity of the cardiac sounds in the fifth right interspace in this case, as in Dr. Hale White's case, can be readily explained by the fact that they were conducted through the consolidated lung and perhaps intensified by the proximity of large pneumonic cavities. The illusion was heightened by the absence of the normal left dulness. But why the abnormal impulse? There could be no doubt about it, and its presence was noted by several observers.

Netley.

\section{NOTE ON A CASE OF QUARTAN AGUE IN NEW ZEALAND.}

BY Robert H. Bakewelt, M.D. ST. AND. \& N.Z., LATE PHYSICIAN TO THE CMRISTCHURCH HOSPITAI, NEW ZEALAND.

THE patient was a woman, aged about forty-five years, who lived near a swamp, but with a hill between her residence and the swamp. For the last month she had been subject to frequent attacks of chills followed by heat and perspiration. From one of these attacks she was suffering when I was called in on August 19th at 8 P.M. The temperature was $101 \cdot 6^{\circ} \mathrm{F}$. and the pulse was about 100 . It appeared on close questioning that these attacks occurred every four days-that is, one, say, on the Monday, the next on the Thursday, always with two clear days. The attacks commenced about 4 P.M. and lasted until the morning; they were accompanied by some headache, great lassitude, aching of the limbs, and the other symptoms of intermittent fever. I ordered $5 \mathrm{gr}$. of sulphate of quinia statim. The dose was to be repeated at $8 \mathrm{~A} . \mathrm{M}$. On calling the next morning at 10 I found that she had taken both doses; there had been no singing in the ears, the temperature had fallen to $96^{\circ}$, and she was ordered $10 \mathrm{gr}$. of quinine daily for two days more. In all she took $30 \mathrm{gr}$. This sufficed to stop the quartan, of which there was no recurrence, and produced no cinchonisma sure sign that it was needed. The rarity of quartan ague must be great, as I have never seen a case for forty-seven years when I resided on the borders of the Essex marshes.

Auckland, New Zealand.

\section{S aflitror}

\section{HOSPITAL PRACTICE, BRITISH AND FOREIGN.}

Nulla autem est alia pro certo noscendi via, nisi quamplurimas et morborum et dissectionum historias, tum aliorum tum proprias collectas habere, et inter se comparare.-MoRGaGNI De Sed. et Caus. Mrorb., lib. iv. Procemium.

\section{ST. THOMAS'S HOSPITAL.}

A CASE OF RUPTURED INTESTINE WITHOUT IBDOMINAL WOUND; LAPAROTOMYY DEATH NEARLY A MONTH LATER.

(Under the care of Mr. W. H. BATTLE.)

RUPTURE of the intestine without any wound of the abdominal wall is probably not very rare yet the number of cases which have been recorded is by no means great. The amount of damage exhibited by the skin of the abdomen is no criterion of the severity of the injury inflicted on the subjacent viscera. The skin may show only a slight abrasion and yet rupture of the liver or the intestine may have occurred. In cases like these, where the wheel of a cart has passed over the abdomen or a severe kick from a horse has been received in the same region, the diagnosis is exceedingly difficult. If the bowel has been ruptured by what signs can it be known? Unfortunately no very definite answer is possible to this question. The great amount and persistence of the collapse may suggest that an injury greater than a mere contusion has been inflicted but it cannot be said that reliance can be placed on this. It was formerly maintained, and the view is still held by many, that absence of liver dulness always occurs in rupture of the stomach or intestine and that the presence of this physical sign is pathognomonic of this condition, but neither of these statements is absolutely true; it usually happens that a rupture of the intestine or of the stomach allows sufficient gas to escape 